\title{
A Case Study on Mucor Septicus (Yellow Fungus) in Post Covid Era
}

\section{Brajpal Tyagi*, Niyati Dhawan and Praveen Kumar Tyagi}

Department of ENT, Harsh ENT Hospital, Ghaziabad, India

*Corresponding Author: Brajpal Tyagi, Department of ENT, Harsh ENT Hospital, Ghaziabad, India.
Received: June 21, 2021

Published: July 26, 2021

(C) All rights are reserved by Brajpal Tyagi., et al

\begin{abstract}
Mucor Septicus is rare fungal disease found in post COVID immunocompromised patient. It is known to produce septecemia if not treated timely. A case of same disease discussed first time in human from Reptiles.
\end{abstract}

Keywords: Mucor Septicus; COVID-19; Delta Variant

\section{Introduction}

The second wave of COVID-19 (Delta Variant) Pandemic has devastated India, and this second wavehas brought another major concern of Fungal Infections. The country has seen a sudden surge in newtypes of fungal infections rapidly since the month of May 2021, especially among those patients who have recently recovered from COVID-19. There is a series of fungal infections which has been witnessed recently in the country, after black and white fungus, the cases of yellow fungus have been recently notified among different cities of India. This Yellow Fungus, which is scientifically known as Mucor-septicus, 1/4 (Fuligo-septica) is the most dangerous one according to the experts.

Case of Yellow Fungus - Mucor-Septicus (Fuligo-Septica)

India' first Yellow Fungus Case (Scientifically referred as Mucorseptica (Fuligo-septica) Post COVID was diagnosed at Harsh ENT Hospital by Professor Dr. BPS Tyagi, a senior ENT Surgeon in Delhi, NCR. The first case of this yellow fungal infection was diagnosed on $23^{\text {rd }}$ May 2021, in a 61 year old male who was recently recovered from the Novel Coronavirus Infection. After 5 days of hospitalization, he was treated with amphotericin B, Surgery and symptomatic treatment and he also suffered from Hypoxia and was on oxygen therapy for almost 5 days. He could not survive due to septicemia and multi organ failure.

This fungus, Mucor-Septicus, belongs to myxomycetes. The first description of this species Mucor-Septicus was given by Carl Lin- naeus in the year 1763. The Swedish Botanist who was also known as father of taxonomy - called this fungus as Mucor-Septicus in his 1763 Species Plantarum [2].

The species was transferred to the genus FULIGO by German botanist Friedrich Heinrich wiggers in 1780 [3].

Mucor-Septicus contains a yellow pigment called "Hemosiderin" [6] and this is the reason why it appears yellow and commonly called the yellow fungus. This fungus is usually found in reptiles and it is believed to have been transferred from dead cells of any such reptile like lizards, which are commonly found in human habitats. It has been reported in a SARS COV-2 patient of uncontrolled diabetes with ketoacidosis.

\section{Probable reasons of mucor-septicus}

The most probable reasons for such infections in humans can be understood as the weakened immunity of the person post COVID-19 (delta Variant). infection due to uncontrolled diabetes/ketoacidosis. People with low immunity post covid-19 recovery may catch this infection by exposure tofungal spores in the environment, which can be easily inhaled. This deadly infection attacks the internal organs of the body as it reaches through nasal passage and disturbs vital body functions. It is assumed that this yellow fungus can infect humans through their presence in soiled food. Poor hygiene and high levels of humidity in unsanitary conditions can be the main cause of its spread in the air and can infect the person 
with weakened immunity. This fungus is not contagious as it cannot spread from one person to another person anyhow.

Signs and symptoms of mucor-septicus

COVID-19 recovered patients with:

- $\quad$ Extreme weakness, Vertigo.

- $\quad$ Loss of appetite, loss of weight.

- Leakage of yellow bloody discharge form nasal cavity.

- $\quad$ Nasal blockage.

- Hypoesthesia (Numbness around nose) and same side of face.

- $\quad$ Sunken eyes.

- $\quad$ CT -PNS-- Indicate pan sinusitis with skull-base bony erosion.

Nasal-endoscopic picture

Yellow color fungus found just near the base of skull.
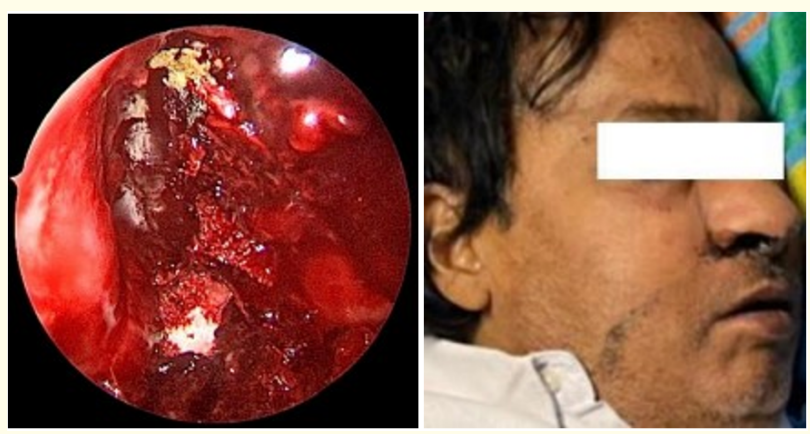

Figure 1

Patients with these symptoms have higher risk of having yellow fungal infection:

- Weakness post COVID-19 recovery.

- Uncontrolled diabetes.

- Weakened immunity after use of steroids.
- Prolonged hospitalization or stay in ICU/Inhalation of Humidified oxygen with unsterilewater.

- Comorbidities/post organ transplant/cancer.

- Voriconazole therapy (used to treat other fungal infections).

Histopathology

Shows viable to necrotic tissue fragments, viable tissue is lined by columnar epithelium and shows benign glands and moderate degree of mixed inflammatoryinfiltrate. Neurotic tissue in invaded by hyphal of Mucor-Septicus. Tissue around fungalhyphal of $\mathrm{Mu}$ cor shows large amount of Hemosiderin pigment angioinvasion is present.
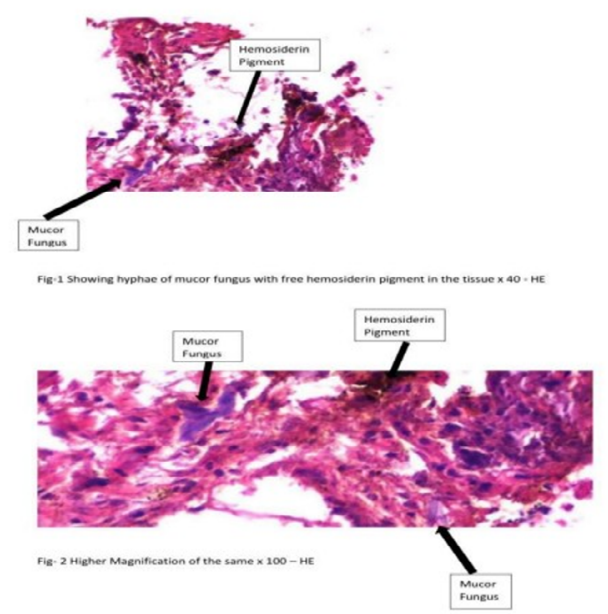

Figure 1

\section{Treatment of mucor-septicus}

Senior ENT Surgeon, Professor Dr. BPS Tyagi treated the patient with extended endoscopic sinus surgery and used the injection Amphotericin B $(7 \mathrm{mg} / \mathrm{kg}$ ) body weight followed by multiple debridementof fungal debris. In spite of all efforts, the patient expired after 5 days because of septicemia.

\section{Relationship to humans $[5,6]$}

In Finland Mucor-Septicus was believed to be used by witches to spoil their neighbor's milk. Thisspecies is known to cause infection in SARS COV-2 injected humans. 


\section{Discussion}

Prof. Tyagi treated this patient with multiple endoscopic debridement with injection Amphotericin B intravenous because this medicine works as a broad spectrum antifungal drug, but since the infection was serious that it had already damaged nasal septum, skull base orbit and brain, Patient could not survive.

\section{Conclusion}

Mucor Septicus (Yellow Fungus) first time detected in human by Professor (Dr) Brajpal Tyagi in Harsh ENT hospital Ghaziabad than detected in five more places in Indian Post-Covid Patient with uncontrolled diabetes.

\section{Bibliography}

1. Linnaeus C. "Species Plantarum ( $2^{\text {nd }}$ edition.)". Stockholm: Impensis Direct. Laurentii Salvii (1763): 1656.

2. Wiggers FH and Weber GH. "Primitiae Florae Holsaticae (in Latin)”. Litteris Mich. Frider. Bartschii Acad. Typogr (1780): 112.

3. Discover Life. "Fuligo". discoverlife (2012).

4. Santili J., et al. "The significance of the spore of the Basidiomycetes (mushrooms and their allies) in bronchial asthma and allergic rhinitis". Annals of Allergy 55.3 (1895): 469-471.

5. Gianini EH., et al. "The allergenic significance of certain fungi is rarely reported as allergens". Annals of Allergy 35.6 (1975): 372-376.

6. "Term introduced by the German pathologist Ernst Neumann (1834-1918) in "Beiträge zur Kenntniss der pathologischen Pigmente". Archiv für pathologische Anatomie und Physiologie, Band 111 (1888): 25-47.

Volume 3 Issue 8 August 2021

(C) All rights are reserved by Brajpal Tyagi., et al. 